\title{
Acúmulo de óleo em sementes de soja cultivadas in vitro e in vivo
}

\section{Oil accumulation in soybean seeds grown in vitro and in vivo}

\author{
José Leonardo Bruno ${ }^{1 *}$; Helder Rodrigues da Silva ${ }^{2}$; \\ Fernando Luiz Massaro Junior ${ }^{3}$; Cássio Egidio Cavenaghi Prete ${ }^{4}$
}

\section{Resumo}

\begin{abstract}
A semente de soja apresenta, cerca de $20 \%$ da sua massa seca em óleo e $40 \%$ em proteína. Esse teor de óleo pode sofrer influência perante as condições ambientais durante o enchimento das sementes, produzindo modificações na sua composição bioquímica. Em condições de cultivo in vivo é difícil controlar esse fator. Nesse sentido, o cultivo in vitro vem auxiliar a pesquisa, pois a semente fica isolada da planta mãe em ambiente controlado. O objetivo deste trabalho foi avaliar os teores de óleo das cultivares BRS 184 e BRS 282 cultivadas in vitro e in vivo. O cultivo in vivo ocorreu em casa de vegetação em vasos com a coleta de sementes no estádio $\mathrm{R}_{8}$, e o cultivo in vitro, em laboratório, utilizando sementes imaturas removidas da planta mãe no estádio $R_{5}$ e cultivadas em meio de cultura líquido contendo $20 \mathrm{mM}, 40 \mathrm{mM}$ e $60 \mathrm{mM}$ de glutamina, e concentração de sacarose de 204,5 mM, com agitação constante por oito dias à temperatura de $25 \pm 0,2{ }^{\circ} \mathrm{C}$. Decorrido o tempo para o cultivo in vitro foi avaliado o ganho de massa de matéria fresca das sementes, e após, em ambos os experimentos, foi determinado o teor de óleo para o cultivo em $\mathrm{R}_{5}$, e para $\mathrm{R}_{8}$. $\mathrm{O}$ acúmulo de óleo nas sementes de soja apresenta interações complexas, variando entre genótipo e condições ambientais tanto no cultivo in vivo quanto in vitro. Há correlação positiva entre ganho de massa e teor de óleo nas sementes.
\end{abstract}

Palavras-chave: Glycine max L.Merril, desenvolvimento da semente, lipídeos

\begin{abstract}
The soybean seed presents around $20 \%$ of oil and $40 \%$ of protein. These levels, during the filling of the seeds, can be influenced by environmental conditions, where are produced changes on its biochemistry composition. The higher temperatures promote the accumulation of protein, and the moderate temperatures favor the oil accumulation. Under in vivo growing conditions the control of these factors is difficult. The in vitro procedure can help the research, because the seed can be isolated from the mother plant in controlled environment. The objective of this experiment was to evaluate the oil content of BRS 184 and BRS 282 in vitro and in vivo. The in vivo procedure, occurred in the greenhouse, with plants per pot and seed collectionin $\mathrm{R}_{8}$, and in vitro procedure, developed in the laboratory, where the immature seeds were taken from the mother plant in $\mathrm{R}_{5}$ stage, cultured with a liquid culture medium containing $20 \mathrm{mM}, 40 \mathrm{mM}$ and $60 \mathrm{mM}$ glutamine, with a constant agitation, during eight days at $25 \pm 0.2{ }^{\circ} \mathrm{C}$, and sucrose concentration of $204.5 \mathrm{mM}$. After the in vitro cultivation time for, the fresh weight gain of the seeds was evaluated, and after both experiments, was determined by the oil content for cultivation in $R_{5}$, and $\mathrm{R}_{8}$. The accumulation of oil in soybean seeds presents a complex interaction, ranging between the genotype and the environmental conditions, under in vivo and in vitro cultivation. There is a positive correlation between production and oil content in seeds.
\end{abstract}

Key words: Glycine max, seed development, lipids

\footnotetext{
1 Discente do Programa de Pós-Graduação em Bioenergia, Universidade Estadual de Londrina, UEL, Londrina, PR. E-mail: leonardobruno@uel.br

2 Discente do Programa de Pós-Graduação em Agronomia, UEL, Londrina, PR. E-mail: heldersilva@uel.br

3 Discente do Programa de Pós-Graduação em Ciência Animal, UEL, Londrina, PR. E-mail: massaro@uel.br

4 Prof., Dr. do Programa de Pós-Graduação em Agronomia, UEL, Londrina, PR. E-mail: cassio@uel.br

* Autor para correspondência
} 
Conforme Wilcox e Guodong (1997) o teor de óleo na semente de soja pode variar de $8,3 \%$ a $27,9 \%$, com valor médio de 19,5\%. Esses autores, analisando o banco mundial de soja, encontraram correlação genética negativa entre o teor de proteína e a produtividade, porém verificaram forte correlação positiva entre o teor de óleo e os componentes de rendimento.

As sementes de soja apresentam um máximo ritmo de acumulação de óleo entre 20 e 40 dias após a floração, durante o estádio $\mathrm{R}_{5}$. Os principais ácidos graxos presentes em sementes de soja em ordem crescente são: esteárico (18:0;4\%), linolênico $(18: 3 ; 7 \%)$, palmítico $(16: 0 ; 11 \%)$, oleico $(18: 1 ; 24 \%)$, e linoleico (18:2;54\%) (WILSON, 2004).

Ainda que a composição de ácidos graxos das sementes de soja não apresente diferença considerável entre os cultivares atuais de soja, há um crescente entendimento de sua regulação gênica e a proporção entre os vários ácidos graxos que definem a qualidade, podendo ser modificada pelo melhoramento genético (WILSON, 2004).

As condições ambientais durante o enchimento das sementes de soja produzem modificações na sua composição bioquímica. De acordo com Dornbos e Mullen (1992), o conteúdo de óleo aumenta com a temperatura média diária durante a etapa $\mathrm{R}_{5}-\mathrm{R}_{6}$ até um ótimo entre $25{ }^{\circ} \mathrm{C}$ e $28{ }^{\circ} \mathrm{C}$. Temperaturas mais altas promovem o acúmulo de proteína e temperaturas amenas favorecem o acúmulo de óleo. Entretanto, Piper e Boote (1999) verificaram que, sob temperaturas médias próximas de $20{ }^{\circ} \mathrm{C}$, as relações se invertem, ou seja, quanto menor a temperatura, menores são os teores de óleo nas sementes de soja.

A correlação inversa entre óleo e proteína nas sementes de soja foi estudada por vários autores (HYMOWITZ et al., 1972; HOWELL; CARTTER, 1953; FARACO et al., 1981), e um dos fatores que influenciaram nesta correlação foram as mudanças de temperatura nos períodos de 20 a 30 e 30 a 40 dias antes da maturação dos grãos de soja, por que exerceram maior influência no acúmulo de óleo, do que as ocorridas em outros períodos.

Pipolo (2002) observou o desenvolvimento das sementes em cultivo in vitro, a partir do estádio $\mathrm{R}_{5}$, com temperatura variando entre 21 e $29^{\circ} \mathrm{C}$, e analisou as concentrações de proteína, óleo e a taxa de acúmulo de massa seca, e corrobora que os teores de óleo e proteína dos grãos de soja são governados geneticamente; porém, fortemente influenciados pelo ambiente.

Entre os fatores ambientais que afetam os teores de óleo e proteína nas cultivares de soja temos o regime pluviométrico e a fixação biológica do nitrogênio. $\mathrm{O}$ estresse hídrico nos estádios iniciais do enchimento da semente aumenta o teor de óleo, enquanto que se ocorrer nos estádios finais diminui o teor de óleo, aumentando o de proteínas. O incremento no teor de proteínas e óleo também é influenciado pela disponibilidade de glutamina na semente (PIPOLO, 2002).

Santos et al. (2010) ao avaliar em cultivo in vitro os teores de óleo e massa fresca de sementes de soja, constataram que em uma mesma cultivar não houve diferença estatística nas concentrações de 20 $\mathrm{mM}, 40 \mathrm{mM}$ e $60 \mathrm{mM}$ de glutamina. Porém, quando compararam as cultivares, o ganho de massa fresca nas concentrações de $40 \mathrm{mM}$ e $60 \mathrm{mM}$ de glutamina foi mais intenso na cultivar CD 206 do que na CD 202. Para a concentração de óleo, verificaram que houve aumento no tratamento com $20 \mathrm{mM}$ de glutamina, e a cultivar CD 202 foi superior em todos os tratamentos com maior acúmulo em relação a $\mathrm{CD}$ 206.

$\mathrm{O}$ cultivo de sementes in vitro em condições controladas permite o estudo dos fatores que regulam o crescimento e a composição da semente de soja sem a interação com a planta mãe, a qual exerce total controle na disponibilidade destes assimilados para a semente. Uma das maneiras de minimizar as dificuldades no estudo é isolar os frutos em formação e cultivá-los em meio artificial adequado (OBENDORF; BYRNE, 1983). 
Trabalhos de Thompson, Madison e Muenster (1977) e Obendorf e Wettlaufer, (1984) demonstraram que a semente de soja apresenta desenvolvimento normal em condições in vitro a partir de um conjunto de materiais, em que a sacarose é a forma primária de translocação de carboidratos, com papel fundamental na partição do carbono para a síntese de proteína e de óleo, e na manutenção do potencial de água, que evita a germinação das sementes durante o cultivo in vitro. Para prevenir a germinação precoce das sementes, a concentração de sacarose deve ser de 204,5 mM, como preconizado por Obendorf e Wettlaufer (1984).

Portanto, diante do contexto apresentado, o objetivo deste trabalho foi avaliar os teores de óleo nas sementes das cultivares BRS 184 e BRS 282 cultivadas in vitro e in vivo.

O trabalho foi conduzido no laboratório de Fitotecnia da Universidade Estadual de Londrina, Paraná. As cultivares utilizadas foram a BRS 184 (FT Guaíra x IAC 13 c), grupo de maturação (GM) 6.7, de ciclo semiprecoce com $24,2 \%$ de óleo e a BRS 282 (Embrapa 48 x BR94-23316), grupo de maturação (GM) 6.9, de ciclo semiprecoce com 18,6\% de óleo (EMBRAPA, 2011).

O experimento para o cultivo das sementes in vitro foi dividido em duas fases, em que a primeira etapa em $\mathrm{R}_{5}$ foi inteiramente casualizada, com esquema fatorial $2 \times 5$, com cinco repetições, constituído do fator A (duas cultivares de soja) e do fator B (três níveis de glutamina 20, 40 e $60 \mathrm{mM}$ ) disponíveis nas soluções de cultivo in vitro; além de, dois tratamentos cultivados in vivo (sementes conduzidas na planta-mãe) em casa de vegetação e colhidas no dia da instalação do cultivo in vitro com zero dia e oito dias, ocasião do termino do cultivo in vitro. A segunda etapa consistiu de um experimento com sementes maduras das cultivares BRS 184 e BRS 282, na fase $\mathrm{R}_{8}$ (final do ciclo das duas cultivares), em seis repetições. Em todos experimentos a variável dependente analisada foi o teor de óleo.
As sementes cultivadas em casa de vegetação, foram semeadas na data de 03/02/2012, em vasos plásticos com volume de nove litros. Foram conduzidas três plantas por vaso, cujo substrato empregado foi um solo de área não agrícola coletado na profundidade de dois metros. Conforme análise de solo, utilizou-se a adubação de $30 \mathrm{~g}$ da formulação NPK 04-14-08 por vaso.

A colheita para o cultivo in vitro foi realizada na data de 10/04/2012, vagens do terço médio da planta no estádio $R_{5}$, com três sementes foram removidas quatro a cinco semanas depois do florescimento (fase linear do crescimento da semente), quando se apresentavam totalmente alongadas e as sementes ocupando entre $70 \%$ a $90 \%$ do lúmen da vagem. As sementes no estádio $R_{5}$ foram submetidas ao desenvolvimento in vitro por oito dias, nos teores de 20, 40 e $60 \mathrm{mM}$ de glutamina.

$\mathrm{O}$ cultivo in vitro foi realizado conforme metodologia descrita por Pipolo (2002), que foi adaptada de Obendorf e Byrne (1983). No dia da instalação dos cultivos, foram preparados frascos de vidro com capacidade de $300 \mathrm{~mL}$, nos quais foram adicionados $10 \mathrm{~mL}$ do meio de cultura completo composto dos seguintes reagentes $\left(\mathrm{KCL}, \mathrm{MgSO}_{4} \cdot 7 \mathrm{H}_{2} \mathrm{O}, \mathrm{MnSO}_{4} \cdot \mathrm{H} 2 \mathrm{O}, \mathrm{ZnSO}_{4} \cdot 7 \mathrm{H}_{2} \mathrm{O}\right.$, $\mathrm{CuSO}_{4} \cdot 5 \mathrm{H}_{2} \mathrm{O}, \mathrm{CaCl}_{2} \cdot 2 \mathrm{H}_{2} \mathrm{O}, \mathrm{Kl}, \mathrm{KH}_{2} \mathrm{PO}_{4}, \mathrm{H}_{3} \mathrm{BO}_{3}$, $\mathrm{Na}_{2} \mathrm{MoO}_{4} \cdot 2 \mathrm{H}_{2} \mathrm{O}, \mathrm{FeSO}_{4} \cdot 7 \mathrm{H}_{2} \mathrm{O}, \mathrm{Na}$ EDTA, glycina, ácido nicotínico, tiamina HCL, piridoxina HCL, sacarose e mio-inositol) e pH do meio ajustado para 6,0. Posteriormente autoclavados a $121^{\circ} \mathrm{C}$ e 18 PSI por 20 minutos.

Para a determinação da massa fresca (MF) das sementes, os frascos com meio de cultura foram pesados antes e após as sementes serem colocadas, no intuito de se obter a massa inicial da semente. Ao final de cada experimento, com oito dias de cultivo, as sementes foram retiradas dos frascos, enxugadas em papel toalha e tiveram suas massas finais determinadas. O acúmulo de massa fresca foi determinado a partir da diferença de valores da massa final em relação a massa inicial. As sementes do cultivo in vivo, foram retiradas da planta-mãe 
e tiveram suas massas determinadas diretamente, com zero dias, no mesmo dia em que se iniciou o cultivo in vitro, e com oito dias após o término do cultivo in vitro.

$\mathrm{Na}$ primeira etapa experimental o teor de óleo foi determinada conforme descrito por Sasser (1990). Para esta análise foram utilizados $100 \mathrm{mg}$ de amostra inicial em estádio $\mathrm{R}_{5}$. $\mathrm{O}$ teor de óleo foi determinado a partir da diferença de massa entre a amostra inicial e o farelo remanescente depois da extração.

Na segunda etapa do experimento, no estádio $R_{8}$, após encerramento do ciclo das plantas, as vagens foram colhidas e debulhadas e as sementes foram submetidas à determinação do teor de óleo. As amostras foram trituradas em moinho refrigerado, marca Tecnal, modelo 631/2, e posterior extração química feita com N-hexano em extrator tipo
Soxhlet. O teor de óleo foi obtido por diferença gravimétrica, após duas horas de extração, com amostras extraídas em duplicata (PREGNOLATTO; PREGNOLATTO, 1985). Nas duas etapas experimentais a determinação do teor de óleo ocorreu de forma gravimétrica.

$\mathrm{O}$ conjunto de dados foi submetido à verificação da normalidade dos resíduos e da homogeneidade das variâncias, e desta forma foi realizada a análise de variância, o teste de comparação de médias Tukey a $5 \%$ de probabilidade e a análise de regressão, com a utilização dos programas estatísticos SISVAR versão 5.3, STATISCA versão 7.0, SIGMAPLOT 11.0 (SISVAR, 2010; SIGMAPLOT, 2008).

Na tabela 1 são apresentados os resultados dos teores de óleo e da massa fresca in vivo e in vitro em diferentes concentrações de glutamina.

Tabela 1. Teor de óleo, em porcentagem (\%), e massa fresca (g/semente) das cultivares BRS 184 e BRS 282 cultivadas in vitro e in vivo com doses de glutamina.

\begin{tabular}{clllllll}
\hline & \multirow{2}{*}{ cultivar } & in vivo & \multicolumn{3}{c}{ dose de glutamina in vitro } & in vivo & \multirow{2}{*}{ média } \\
\cline { 4 - 6 } & & dia zero & $20 \mathrm{mM}$ & $40 \mathrm{mM}$ & $60 \mathrm{mM}$ & oito dias & \\
\hline \multirow{2}{*}{${ }^{1}$ Teor de óleo\% } & BRS 184 & $18,19 \mathrm{Aab}$ & $16,33 \mathrm{Ab}$ & $17,81 \mathrm{Aab}$ & $17,91 \mathrm{Aab}$ & $19,27 \mathrm{Aa}$ & $17,90 \mathrm{~A}$ \\
& BRS 282 & $15,73 \mathrm{Bab}$ & $15,46 \mathrm{Ab}$ & $16,21 \mathrm{Aab}$ & $17,90 \mathrm{Aa}$ & $17,80 \mathrm{Aab}$ & $16,62 \mathrm{~B}$ \\
& média & $16,96 \mathrm{ab}$ & $15,90 \mathrm{~b}$ & $17,01 \mathrm{ab}$ & $17,90 \mathrm{a}$ & $18,54 \mathrm{a}$ & \\
\hline${ }^{2}$ Massa & BRS 184 & $0,17 \mathrm{Ac}$ & $0,38 \mathrm{Aa}$ & $0,30 \mathrm{Ab}$ & $0,22 \mathrm{Abc}$ & $0,21 \mathrm{Ac}$ & \\
$\begin{array}{c}\text { Fresca (g/ por } \\
\text { semente) }\end{array}$ & BRS 282 & $0,17 \mathrm{Aa}$ & $0,23 \mathrm{Ba}$ & $0,19 \mathrm{Ba}$ & $0,21 \mathrm{Aa}$ & $0,19 \mathrm{Aa}$ & \\
\hline
\end{tabular}

${ }^{1}$ Coeficiente de variação $(\mathrm{CV}) \%=7,69$

${ }^{2} \mathrm{CV} \%=18,46$

* Médias seguidas de mesma letra, maiúscula na coluna e minúscula na linha, não diferem a 5\% de probabilidade pelo teste Tukey.

Fonte: Elaboração dos autores.

Os resultados obtidos com o teor de óleo, demonstram que na média a cultivar BRS 184 foi estatisticamente superior à BRS 282. O teor de óleo inicial das sementes, imediatamente retiradas da planta, foi superior na cultivar BRS 184, valor também observado na média geral dos dados (Tabela 1).

Dentro dos tratamentos, houve diferença estatística no tratamento in vivo, imediatamente após a retirada das sementes, em que a cultivar BRS 184 obteve maior teor de óleo que a cultivar BRS 282.

Quando comparados os tratamentos in vivo $e$ in vitro, observa-se que, para a cultivar BRS 184, o tratamento in vivo, aos oito dias, apresenta diferença estatística em relação a dose de glutamina de $20 \mathrm{mM}$, para o teor de óleo e para a BRS 282, o tratamento de $60 \mathrm{mM}$ foi estatisticamente superior ao $20 \mathrm{mM}$ (Tabela 1). 
$\mathrm{Na}$ avaliação dos teores de massa fresca, no cultivo in vivo, as duas cultivares apresentavam teores semelhantes na época de retirada das sementes da planta-mãe e não diferiram estatisticamente entre si, tanto a zero, quanto a oito dias (Tabela 1).

No cultivo in vitro, nos tratamentos de 20 $\mathrm{mM}$ e $40 \mathrm{mM}$ de glutamina, a cultivar BRS 184 foi superior a cultivar BRS 282 (Tabela 1).

Entre os tratamentos aplicados à cultivar BRS 184, o que mais se destacou diante da variável
Massa Fresca foi o de cultivo in vitro, com $20 \mathrm{mM}$ de glutamina conforme Santos et al. (2010), sendo superior a todos os tratamentos, inclusive quando comparado ao cultivo in vivo. Esse tratamento também foi estatisticamente superior aos demais, quando a variável era Massa Fresca (MF). (Tabela 1)

$\mathrm{Na}$ figura 1, são apresentados os resultados de produção em g por vaso e teor de óleo em \% das cultivares BRS 184 e BRS 282.

Figura 1. Produção de sementes em g/ semente da cultivar BRS 282 e BRS 184 e o teor de óleos \% no estádio R .

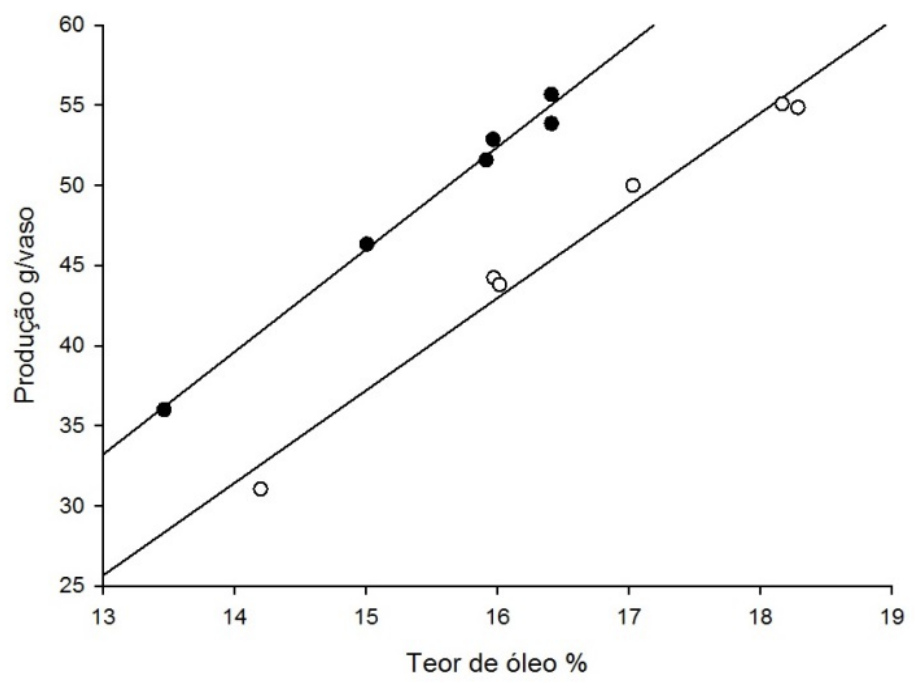

- produção vs teor de óleo\% (cultivar 282), $y=-49,8243+6,3894 x, r^{2}=0,9908, p=0,00003$

produção vs teor de óleo\% (cultivar 184), $y=-49,2886+5,7669 x, r^{2}=0,9805, p=0,0001$

Fonte: Elaboração dos autores.

Avaliando os dados da segunda etapa experimental no estádio $\mathrm{R}_{8}$, evidenciou-se que a BRS 184 apresentou teor de óleo variando de $14,19 \%$ a $18,28 \%$ com uma média de $16,61 \%$, o que é superior a obtida com a BRS 282, cujo teor de óleo variou de $13,46 \%$ a $16,4 \%$ com média de $15,52 \%$; entretanto a produção em g/vaso, a BRS 282 apresentou maior produtividade com média de 49,38 g/vaso, quando comparado a BRS 184 com média de 46,50 g/vaso (Figura 1). Em ambas as cultivares constatou-se correlação entre a produção (g/vaso) e teor de óleo\% de acordo com a equação, para BRS 282 cujo maior valor obtido foi de 53,86 para a produção em g/vaso e 16,4 \% no teor de óleo. Para a BRS 184 o maior valor obtido foi de 55,08 para produção em g/vaso e 18,28 \% no teor de óleo, Wilcox e Guodong (1997), também verificaram correlação entre a produção (g/vaso) e teor de óleo $\%$.

O acúmulo de óleo nas sementes de soja apresenta interações complexas, e varia entre genótipos e condições ambientais no cultivo in vivo 
e no cultivo in vitro. Verifica-se neste trabalho na forma de cultivo in vivo a correlação positiva entre a produtividade e o teor de óleo. A cultivar BRS 184 apresenta maior teor de óleo quando comparada com a BRS 282, mas o teor de óleo obtido nos experimento in vivo e in vitro (média 17,9 \%) não alcançaram os níveis relatados no boletim técnico da EMBRAPA (2011/2012), com níveis em torno de $24 \%$ de óleo.

\section{Referências}

DORNBOS, D. L.; MULLEN, R. E. Soybean and oil contentes and fatty acid composition adjustment by drought and temperature. Jounal of American Oil Chemistry Socity, Iowa, v. 59, n. 3, p. 230-232, 1992.

EMPRESA BRASILEIRA DE PESQUISA AGROPECUÁRIA - EMBRAPA. Cultivares de soja 2011/2012 região Centro -Sul do Brasil. Londrina: Empresa Brasileira de Pesquisa Agropecuária, 2011. 52 p.

FARACO, M. H.; MORAES, R. M.; TEIXEIRA, J. P. F.; SILVA, M. T. R.; MASCARENHAS, H. A. A. Influência de anos agrícolas sobre a composição e acúmulo de óleo em grãos de soja CV Santa Rosa In: SEMINÁRIO NACIONAL DE PESQUISA DE SOJA, 1., 1981, Brasilía. Anais. Londrina: EMBRAPA/CNPSO, 1981. p. 544-553.

HOWELL, R. W.; CARTTER, J. L. Physiological factors affecting composition of soybeans. I - response of oil and other constituents of soybeans to temperature under controlled conditions. Agronomy Journal, Madison, v. 45 , n. 11 , p. 526-528. 1953.

HYMOWITZ, T.; COLLINS, F. I.; PANCZNER, J.; WALKER, W. M. Relationship between the content of oil, protein, and sugar in soybean seed. Agronomy Journal, Madison, v. 64, n. 5, p. 613-616, 1972.

OBENDORF, R. L.; WETTLAUFER, S. H. Precocious germination during in vitro growth of soybean seeds. Plant Physiology, Ithaca, v. 76, n. 6, p. 1024-1028, 1984.

OBENDORF, R. L. R.; BYRNE, M. C. Soya bean seed growth maturation by in vitro pod culture. Annals of Botany, Ithaca, v. 51, n. 2, p. 217-227, 1983.
PREGNOLATTO, W.; PREGNOLATTO, N. P. Normas analíticas do Instituto Adolfo Lutz: métodos químicos e físicos para análise de alimentos. 3. ed. São Paulo: Secretaria Estadual da Saúde, 1985. v. 1, p. 533.

PIPER, E. L.; BOOTE, K. J. J. A. Temperature and cultivar effects on soybean seed oil and protein percentages. OilChemists' Society, Gainesville, v. 76, n. 10, p. 1233-1241, 1999.

PIPOLO, A. E. Influência da temperatura sobre as concentrações de proteína e óleo em sementes de soja (Glycine Max (L) Merril). 2002. Tese (Doutorado em Fitotecnia) - Escola Superior de Agricultura Luiz de Queiroz, Piracicaba.

SANTOS, E. L.; PÍPOLO, A. E.; FARIA, R. T.; PRETE, C. E. C. Influence of genotype on protein and oil concentration of soybean seeds. Brazilian Archives of Biology and Technology, Curitiba, v. 53, n. 4, p. 793-799, 2010.

SASSER, M. Identification of bacteria by gás chormatografia of cellular fatty acids. MIDI,Technical Note 101. Newark, DE: MIDI, 1990. 7 p.

SIGMAPLOT, Systat Software. Exact graphs and data analysis statistical package for windows, version 11. San Jose, 2008.

FERREIRA, D. F. Sisvar: a computer statistical analysis system. Ciência e Agrotecnologia, Lavras, v. 35, n. 6, p. 1039-1042, 2011.

THOMPSON, J. F.; MADISON, J. T.; MUENSTER, A. E. In vitro culture of immature cotyledons of soya bean [Glycine Max (L) Merrill]. Annals of Botany, London, v. 41, n. 1, p. 29-49. 1977.

WILCOX, J. R.; GUODONG, Z. Relatioship between seed yield and seed protein in determinate and indeterminate soybean populations. Crop Science, West Lafayette, v. 37, n. 2, p. 361-364. 1997.

WILSON, R. E. Seed composition. In: BOERMA, H. R. J. E. (Ed.). Soybeans: improvement, production and uses. Madison, ASA/CSSA/SSSA, 2004. p. 621-677. 